Research Paper

\title{
A Randomized, Double-blind, Non-inferiority Trial of Magnesium Sulphate versus Dexamethasone for Pre- vention of Postoperative Sore Throat after Lumbar Spinal Surgery in the Prone Position
}

\author{
Jin Ha Park¹, Jae-Kwang Shim², Jong-Wook Song², Jaewon Jang¹, Ji Hoon Kim¹, Young-Lan Kwak² ${ }^{凶}$ \\ 1. Department of Anesthesiology and Pain Medicine, Yonsei University College of Medicine \\ 2. Department of Anesthesiology and Pain Medicine and Anesthesia and Pain Research Institute, Yonsei Cardiovascular Research Institute, Yonsei University \\ College of Medicine, Seoul, Republic of Korea.
}

$\square$ Corresponding author: Young-Lan Kwak, M.D., Ph.D., Department of Anesthesiology and Pain Medicine and Anesthesia and Pain Research Institute, Yonsei Cardiovascular Research Institute, Yonsei University College of Medicine, 50 Yonsei-ro, Seodaemun-gu, Seoul, 03722, Republic of Korea. Phone: 82-2-2228-2420; Fax: 82-2-312-7185; E-mail: ylkwak@yuhs.ac

( 2015 Ivyspring International Publisher. Reproduction is permitted for personal, noncommercial use, provided that the article is in whole, unmodified, and properly cited. See http://ivyspring.com/terms for terms and conditions.

Received: 2015.05.31; Accepted: 2015.09.02; Published: 2015.09.20

\begin{abstract}
Background: Postoperative sore throat (POST) is a frequent complication of tracheal intubation, particularly after surgery in the prone position. We designed this study to validate the non-inferiority of magnesium sulphate against dexamethasone for prevention of POST after lumbar spinal surgery.

Methods: One hundred and forty-six patients were randomly allocated to receive either magnesium or dexamethasone. Before anesthetic induction, the magnesium group $(n=73)$ received magnesium sulphate $30 \mathrm{mg} / \mathrm{kg}$ followed by $10 \mathrm{mg} / \mathrm{kg} / \mathrm{h}$ by continuous infusion until the end of surgery. The dexamethasone group $(n=73)$ received dexamethasone $8 \mathrm{mg}$. The primary endpoint was the overall incidence of POST, which was assessed serially over $48 \mathrm{hr}$ postoperatively. The predefined margin of non-inferiority for magnesium against dexamethasone was $15 \%$.

Results: Overall incidences of POST at rest $(50.7 \%$ versus $49.3 \%$ in the magnesium and dexamethasone group, respectively, $p=0.869)$ and swallowing $(65.8 \%$ versus $61.6 \%$ in the magnesium and dexamethasone group, respectively, $p=0.606$ ) were not different between the groups. The upper limit of the $90 \%$ confidence interval, which must be lower than the predefined margin of non-inferiority to prove the non-inferiority of magnesium sulphate against dexamethasone, for at rest and swallowing were $14.97 \%(p=0.0496)$ and $17.19 \%(p=0.0854)$, respectively. The incidences and severities of POST and hoarseness were also not different between the groups throughout the study period.
\end{abstract}

Conclusions: Prophylactic magnesium sulphate appears to be non-inferior to dexamethasone for the prevention of POST at rest in patients undergoing lumbar spinal surgery in the prone position.

Key words: Dexamethasone; Magnesium; Postoperative sore throat; Prone position

\section{Introduction}

Despite being perceived as a minor complication, postoperative sore throat (POST) is common after general anesthesia, occurring in $30 \%$ to $65 \%$ of patients [1,2]. POST contributes to patient dissatisfaction and physical discomfort during the recovery phase [3]. POST is attributed to multiple perioperative conditions, including local irritation and inflammation of airway [4], large size of the tracheal tube [5], increased duration of surgery [6], movement of tracheal tube and cuff during position change [1], airway damage after intubation using rigid stylet $[1,7]$, and prone position [8]. 
In lumbar spinal surgery performed in the prone position, the incidence and severity of POST is expected to be high and of great magnitude as it mandates the use of wire-reinforced tracheal tube having larger outer diameter [9] requiring concomitant use of a rigid stylet, and two times of position change while being intubated. Thus, efforts to reduce the occurrence of POST would be of high priority in this subset of patients while evidence is scarce in that regard.

Numerous pharmacological and non-pharmacological approaches to prevent or minimize the incidence and severity of POST have been tried with conflicting results $[4,10,11]$. Among them, dexamethasone possessing pluripotent action mechanisms has been proposed as a relatively well-proven preventive measure for POST $[2,12]$, although possible inherent complications such as gastric ulcer, infection and hyperglycemia limit its widespread use [13].

Magnesium, an N-methyl-D-aspartate (NMDA) receptor antagonist, has potential advantages to play a beneficial role in reducing POST through multiple mechanisms as well, such as anti-nociceptive and anti-inflammatory effects by inhibiting NMDA receptor-mediated calcium influx $[14,15]$. Indeed, there are evidences to suggest that magnesium can be used for reducing the incidence of POST $[16,17]$. The effect of magnesium on POST, however, has rarely been compared with other agents shown to have efficacies in that regard, especially in patients undergoing lumbar spinal surgery in the prone position who are at increased risk of developing POST.

Therefore, we designed a non-inferior randomized controlled trial to compare the efficacy of magnesium sulphate with dexamethasone for reducing POST in patients undergoing lumbar spinal surgery in the prone position.

\section{Methods}

\section{Ethics}

This prospective, randomized, double-blind non-inferiority study was conducted at Yonsei University Health System, Seoul, Republic of Korea. Ethical approval for this study (IRB number, 4-2013-0385) was provided by the Institutional Review Board of Yonsei University Health System, Seoul, Republic of Korea. This study was registered at www.ClinicalTrials.gov (identified: NCT01923831). Informed consents were obtained from all patients before enrollment in the study.

\section{Patient selection}

After obtaining informed written consent from all patients, 146 patients requiring general anesthesia with tracheal intubation in the prone position for elective lumbar spinal surgery, using standard poste- rior approach, were enrolled. Inclusion criteria were 20 to 65 year old patients with ASA physical status I-II. Exclusion criteria were pre-existing hoarseness or sore throat, upper respiratory tract infection, use of corticosteroids and calcium channel blockers, allergy to magnesium sulphate, Cormack-Lehane grade 3 or 4, anticipated difficult intubation (a Mallampati score III or IV, underlying facial anomaly or a mouth opening less than $40 \mathrm{~mm}$ ), more than two attempts at intubation, impaired renal function, diabetes mellitus or immunocompromized patients.

\section{Study design}

Patients were randomly allocated into either magnesium group $(n=73)$ or dexamethasone group $(n=73)$ using a computerized randomization table the day before operation by an investigator (J.J), not involved with patient care. For each patient, group assignments were kept in sequentially numbered opaque, sealed envelopes that were opened by an investigator (J.H.K) not involved with patient care.

In the magnesium group, magnesium sulphate $30 \mathrm{mg} / \mathrm{kg}$ in a total of $100 \mathrm{ml}$ normal saline was given for $10 \mathrm{~min}$ before the induction of anesthesia, followed by continuous infusion of magnesium sulphate at $10 \mathrm{mg} / \mathrm{kg} / \mathrm{h}$ until the end of operation. The chosen dose of magnesium sulphate in this study was determined according to a previous study reporting efficacy of magnesium for pain control with minimal hemodynamic derangement [18]. In the dexamethasone group, dexamethasone $8 \mathrm{mg}$ in $100 \mathrm{ml}$ normal saline was given for $10 \mathrm{~min}$ before the induction of anesthesia, followed by continuous infusion of equivalent volume of $0.9 \%$ saline as in the magnesium group. Infusion of magnesium sulphate or normal saline was discontinued at skin closure. Study drugs were prepared in syringes labelled 'study drug' by an anesthesiologist, not involved in the study.

\section{Perioperative management}

Anesthesia was provided by an anesthesiologist (J.K.S), blinded to the patients' group allocation. Upon arrival at the operating room, standard monitoring devices were applied. General anesthesia was induced with propofol $1.5 \mathrm{mg} / \mathrm{kg}$ and remifentanil $0.3-0.5 \mu \mathrm{g} / \mathrm{kg} / \mathrm{min}$, and rocuronium $0.6 \mathrm{mg} / \mathrm{kg}$ was used for neuromuscular blockade. After loss of all four twitches from train-of-four (TOF) stimulation of the ulnar nerve, direct laryngoscopy was performed using either a Macintosh 3 or 4 laryngoscope blade. Wire-reinforced tracheal tubes (Mallinckrodt ${ }^{\mathrm{TM}}$ Lo-Contour cuffed reinforced oral/nasal tracheal tube, Covidien ${ }^{\mathrm{TM}}$, Mansfield, OH, USA) of size 8.0 $\mathrm{mm}$ and $7.0 \mathrm{~mm}$ internal diameter were inserted for male and female patients, respectively, with the aid of 
a rigid stylet. Application of external laryngeal pressure to aid tracheal intubation, and Cormack and Lehane grade were recorded. All intubation procedures were performed by an anesthesiologist with an at least 2 years of experience, not involved in this study. The intra-cuff pressure was monitored with a noninvasive manometer every $15 \mathrm{~min}$ and adjusted between $20-25 \mathrm{cmH}_{2} \mathrm{O}$ during operation.

Anesthesia was maintained with sevoflurane $1.5-2.5 \%$ in an air-oxygen mixture (fraction of inspired oxygen $=0.5)$ and $0.1-0.3 \mu \mathrm{g} / \mathrm{kg} / \mathrm{min}$ remifentanil infusion. Neuromuscular blockade was monitored using TOF stimulation of ulnar nerve. If hypotension occurred, reduction in mean arterial pressure below $20 \%$ of preanesthetic value, $200 \mathrm{ml}$ of either Hartmann's solution or normal saline was given. If hypotension persisted for more than 10 minutes, ephedrine bolus (4mg, repeated) was administered and recorded. If hypotension could not be treated by incremental doses of ephedrine, either phenylephrine or noradrenaline infusion was started. In all patients, prone positioning was done using the Wilson frame with the subject's face resting on a foam cushion (Gentle Touch Headrest Pillow with Intubation Slot, Mizuho OSI, Tokyo, Japan) without rotation of the head.

At the beginning of the skin closure, an i.v. patient-controlled analgesia (PCA) device (Accufuser plus ${ }^{\circledR}$, P2015M, Woo Young Medical Co. Ltd, Korea) containing fentanyl $20 \mu \mathrm{g} / \mathrm{kg}$ and ramosetron $0.3 \mathrm{mg}$ in normal saline with a total volume of $100 \mathrm{ml}$ was connected. This was programmed to deliver $2 \mathrm{~mL} / \mathrm{h}$ as background infusion with a $0.5 \mathrm{ml}$ bolus at $15 \mathrm{~min}$ lockout period. At the end of the surgery, oxygen $100 \%$ was administered and residual neuromuscular blockade was antagonized with pyridostigmine 0.3 $\mathrm{mg} / \mathrm{kg}$ and glycopyrrolate $0.004 \mathrm{mg} / \mathrm{kg}$ when the four responses were detected in TOF stimulation. Tracheal tube was removed after patients were fully awake. Duration from anesthetic discontinuation to response to verbal command and tracheal extubation were recorded. The patients were allowed to receive tramadol $1 \mathrm{mg} / \mathrm{kg}$ i.v. if they complained of pain $>5$ $\mathrm{cm}$ on visual analog scale (VAS) score in recovery room and ward. Total number of additional rescue analgesics on recovery room and ward for postoperative analgesia was recorded.

\section{Outcomes}

Assessed primary efficacy variables were the overall incidence and severity of POST during the study period. The variables were assessed by an anesthesiologist (J.W.S), blinded to the group allocation, using Harding's direct questionnaire [19]. The intensity of sore throat was assessed at rest and on swallowing using a $0-10 \mathrm{~cm}$ VAS where a score of 0 meant no pain and a score of 10 represented the worst pain imaginable.

Assessed secondary efficacy variables were intensity of hoarseness using a 4-graded scale $[0=$ no hoarseness, $1=$ mild hoarseness (noticed by the patient only), 2 = severe hoarseness (noticed at the time of the interview by the personnel), $3=$ aphonia (inability to speak)], and the following variables: VAS scores of wound pain at rest and upon moving, additional requirement of rescue analgesics, episodes of postoperative nausea and vomiting (PONV). These variables were also assessed by an anesthesiologist (J.W.S).

All above mentioned variables were assessed serially at 4 periods: 0 to 1,1 to 6,6 to 24 , and 24 to 48 hours after operation. Any complication associated with magnesium sulphate (e.g., diarrhea, hypotension) and dexamethasone (e.g., poor glycemic control) was also assessed.

This study was conducted without any changes of methods or trial outcomes after trial commencement. An anesthesiologist (J.H.P) blinded to group allocation was responsible for collecting data except primary and secondary efficacy variables.

\section{Sample size calculation}

The institutional review board highly recommended not designating a control group in this study design, for it would be unethical to neglect the increased risk of POST in the control group. Therefore, this study was performed as a non-inferiority trial, designating dexamethasone, the commonly used drug for preventing POST, as the comparison for the effects of magnesium toward POST. As POST had not been addressed in this studied patients, we used the highest published incidence of POST for sample size calculation. Previous studies have demonstrated that the highest incidence of POST with magnesium and dexamethasone were $23 \%$ and $27 \%$, respectively $[2,16]$. The number of patients required for each group was determined on the basis of the non-inferiority hypothesis. For non-inferiority of the magnesium group versus dexamethasone group, a maximum difference of $15 \%$ (margin of non-inferiority) on the incidence of POST was considered as acceptable. Therefore, we calculated that a study with 65 patients per group would have at least $95 \%$ power, with one-sided type I error of 0.025 . Taking into consideration of the 10 percent dropout rate, we decided to enroll 73 patients in each group.

\section{Statistical analysis}

Statistical analyzes were performed using SAS version 9.3 (SAS Institute Inc., Cary NC, USA). Categorical variables were analyzed using chi-square test 
or Fisher's exact test and defined as number and percentage. Continuous variables were expressed as mean \pm SD or median [interquartile range] according to the normality, using Student's $t$-test or Mann-Whitney $\mathrm{U}$ test, as appropriate. $\mathrm{P}$ values of $<0.05$ were considered significant. As secondary analysis, we used Bonferroni correction to compare all pairs of four evaluation time-points, 0 to 1,1 to 6,6 to 24,24 to 48 hours after operation, for multiple comparisons between the groups and adjusted $\mathrm{P}$ value of $<0.0125$ were considered significant.

\section{Results}

\section{Baseline demographic data}

Among the 180 patients assessed for eligibility, 146 patients who met the inclusion criteria and agreed to participate in this study were enrolled between Aug 2013 and Sep 2014 (Figure 1). Of the 146 patients, study could be completed in all patients and thus, no patient was excluded from statistical analysis.

The patients' characteristics and operative data were not different between the groups (Table 1). Duration from anesthetic discontinuation to response to verbal command and tracheal extubation, and the amount of remifentanil infused were similar between the groups. None of the patients in the magnesium group demonstrated signs of prolonged neuromuscular blockade.

Table 1. Baseline characteristics of surgical and operative data of patients

\begin{tabular}{llll}
\hline Variables & $\begin{array}{l}\text { Magnesium } \\
(\mathrm{n}=73)\end{array}$ & $\begin{array}{l}\text { Dexame- } \\
\text { thasone } \\
(\mathrm{n}=73)\end{array}$ & $\begin{array}{l}\mathrm{p} \\
\text { value }\end{array}$ \\
\hline Age (yrs) & $51 \pm 12$ & $51 \pm 12$ & 0.852 \\
Female (n) & $32(44 \%)$ & $31(43 \%)$ & 0.999 \\
Height (cm) & $165 \pm 10$ & $166 \pm 10$ & 0.442 \\
Weight (kg) & $67 \pm 12$ & $67 \pm 19$ & 0.965 \\
ASA (I/II) & $26 / 47$ & $33 / 40$ & 0.238 \\
Hypertension (n) & $23(32 \%)$ & $14(19 \%)$ & 0.087 \\
Cerebrovascular accident (n) & $3(4 \%)$ & $4(6 \%)$ & 0.999 \\
Smoking (non/past/current) & $40 / 14 / 19$ & $52 / 13 / 8$ & 0.115 \\
Diagnosis (spinal stenosis/disc herni- & $37 / 36$ & $38 / 35$ & 0.868 \\
ation) & & & \\
Surgery (posterior fu- & $30 / 43$ & $36 / 37$ & 0.318 \\
sion/laminectomy) & & & \\
Duration of tracheal intubation (min) & $140[100-200]$ & $130[86-187]$ & 0.371 \\
Duration of surgery (min) & $190[140-243]$ & $170[138-245]$ & 0.300 \\
Cormack-Lehane grade (1/2) & $49 / 24$ & $58 / 15$ & 0.092 \\
External compression (n) & $23(32 \%)$ & $14(19 \%)$ & 0.087 \\
Time to response to verbal command & $10[6-13]$ & $10[7-12]$ & 0.831 \\
(min) & & & \\
Time to extubation (min) & $11[9-14]$ & $11[9-13]$ & 0.562 \\
Total amount of rocuronium (mg) & $39[35-44]$ & $40[34-46]$ & 0.925 \\
\hline Values are & & & \\
\hline
\end{tabular}

Values are number of patients (percentage), mean \pm standard deviation or median [interquartile range].

ASA, American Society of Anesthesiologists Physical Status Classification.

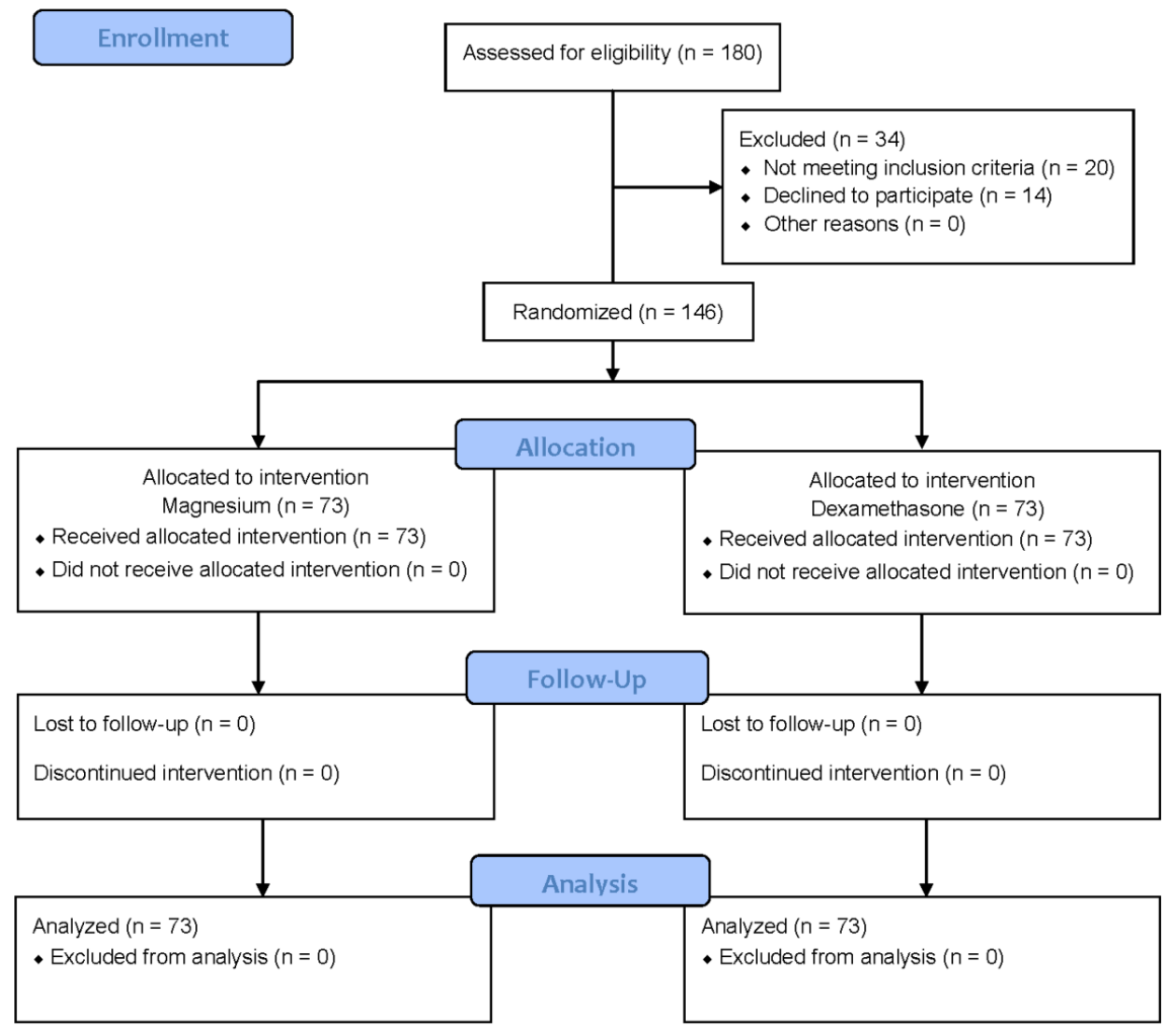

Figure 1. Flow chart describing recruitment, allocation, follow-up and analysis 


\section{Efficacy data}

\section{Primary outcome}

The incidence and severity of POST are shown in Table 2. Overall incidences of POST at rest $(50.7 \%$ versus $49.3 \%$ in the magnesium group and dexamethasone group, respectively, $\mathrm{p}=0.869$ ) and swallowing $(65.8 \%$ versus $61.6 \%$ in the magnesium group and dexamethasone group, respectively, $\mathrm{p}=0.606$ ) were not significantly different between the groups. Respective incidences of POST, which were serially assessed at various predefined time points were also all similar between the groups. Overall, the upper limit of the $90 \%$ confidence interval for overall incidence, which must be lower than the predefined margin of non-inferiority $(15 \%)$ to prove the non-inferiority of magnesium sulphate against dexamethasone, were $14.97 \%(\mathrm{p}=0.0496)$ and $17.19 \%(\mathrm{p}=0.0854)$ at rest and swallowing, respectively. The upper limits of the $90 \%$ confidence interval of the serially assessed time points of assessment were all below 15\% (all $p$ values $<0.05$ ) except at 6-24 h on swallowing, which was $18.86 \%$ (p $=0.13$ ) (Figure 2). The VAS scores for the severity of POST were all similar between the groups with median values ranging from 1 to 2 at all time points of assessment. The number of patients who experienced POST VAS score of higher than 4 during the study period was $11(15.1 \%)$ and $12(16.4 \%)$ in the magnesium and dexamethasone group, respectively $(\mathrm{p}=$ 0.820). The number of patients who indicated POST
VAS score 1 at least once during the study period was $39(53.4 \%)$ and $38(52.1 \%)$ in the magnesium group and dexamethasone group, respectively $(p=0.868)$.

Table 2. Incidence and severity of postoperative sore throat

\begin{tabular}{|c|c|c|c|}
\hline Evaluation time points & $\begin{array}{l}\text { Magnesium } \\
(\mathrm{n}=73)\end{array}$ & $\begin{array}{l}\text { Dexamethasone } \\
(\mathrm{n}=73)\end{array}$ & $\mathrm{p}$ value \\
\hline \multicolumn{4}{|l|}{ Overall incidence } \\
\hline sore throat at rest & $37(50.7 \%)$ & $36(49.3 \%)$ & 0.869 \\
\hline sore throat on swallowing & $48(68.5 \%)$ & $45(61.6 \%)$ & 0.606 \\
\hline \multicolumn{4}{|c|}{ 0-1 hour (incidence/severity*) ${ }^{\dagger}$} \\
\hline sore throat at rest & $32(43.8 \%) / 1$ [1-2] & $\begin{array}{l}34(46.6 \%) / 2 \\
{[1-3]}\end{array}$ & $\begin{array}{l}0.739 / \\
0.021\end{array}$ \\
\hline sore throat on swallowing & $43(58.9 \%) / 2$ [1-2] & $\begin{array}{l}43(58.9 \%) / 2 \\
{[1-3]}\end{array}$ & $\begin{array}{l}0.999 / \\
0.103\end{array}$ \\
\hline \multicolumn{4}{|c|}{ 1-6 hour (incidence/severity*) $\dagger$} \\
\hline sore throat at rest & $26(35.6 \%) / 1$ [1-2] & $\begin{array}{l}25(34.2 \%) / 2 \\
{[1-2]}\end{array}$ & $\begin{array}{l}0.999 / \\
0.255\end{array}$ \\
\hline sore throat on swallowing & $36(49.3 \%) / 2$ [1-2] & $\begin{array}{l}35(47.9 \%) / 2 \\
{[1-3]}\end{array}$ & $\begin{array}{l}0.868 / \\
0.164\end{array}$ \\
\hline \multicolumn{4}{|c|}{ 6-24 hour (incidence/severity*) ${ }^{\dagger}$} \\
\hline sore throat at rest & $13(17.8 \%) / 1$ [1-3] & $\begin{array}{l}10(13.7 \%) / 2 \\
{[1-3]}\end{array}$ & $\begin{array}{l}0.496 / \\
0.499\end{array}$ \\
\hline sore throat on swallowing & $22(30.1 \%) / 1[1-3]$ & $\begin{array}{l}17(23.3 \%) / 2 \\
{[1-2.5]}\end{array}$ & $\begin{array}{l}0.350 / \\
0.367\end{array}$ \\
\hline \multicolumn{4}{|c|}{ 24-48 hour (incidence/severity*) ${ }^{\dagger}$} \\
\hline sore throat at rest & $7(9.6 \%) / 1[1-1]$ & $4(5.5 \%) / 1[1-1]$ & $\begin{array}{l}0.347 / / \\
0.450\end{array}$ \\
\hline sore throat on swallowing & $12(16.4 \%) / 1$ [1-2.75] & $\begin{array}{l}8(11.0 \%) / 1 \\
{[1-1]}\end{array}$ & $\begin{array}{l}0.336 / \\
0.243\end{array}$ \\
\hline
\end{tabular}

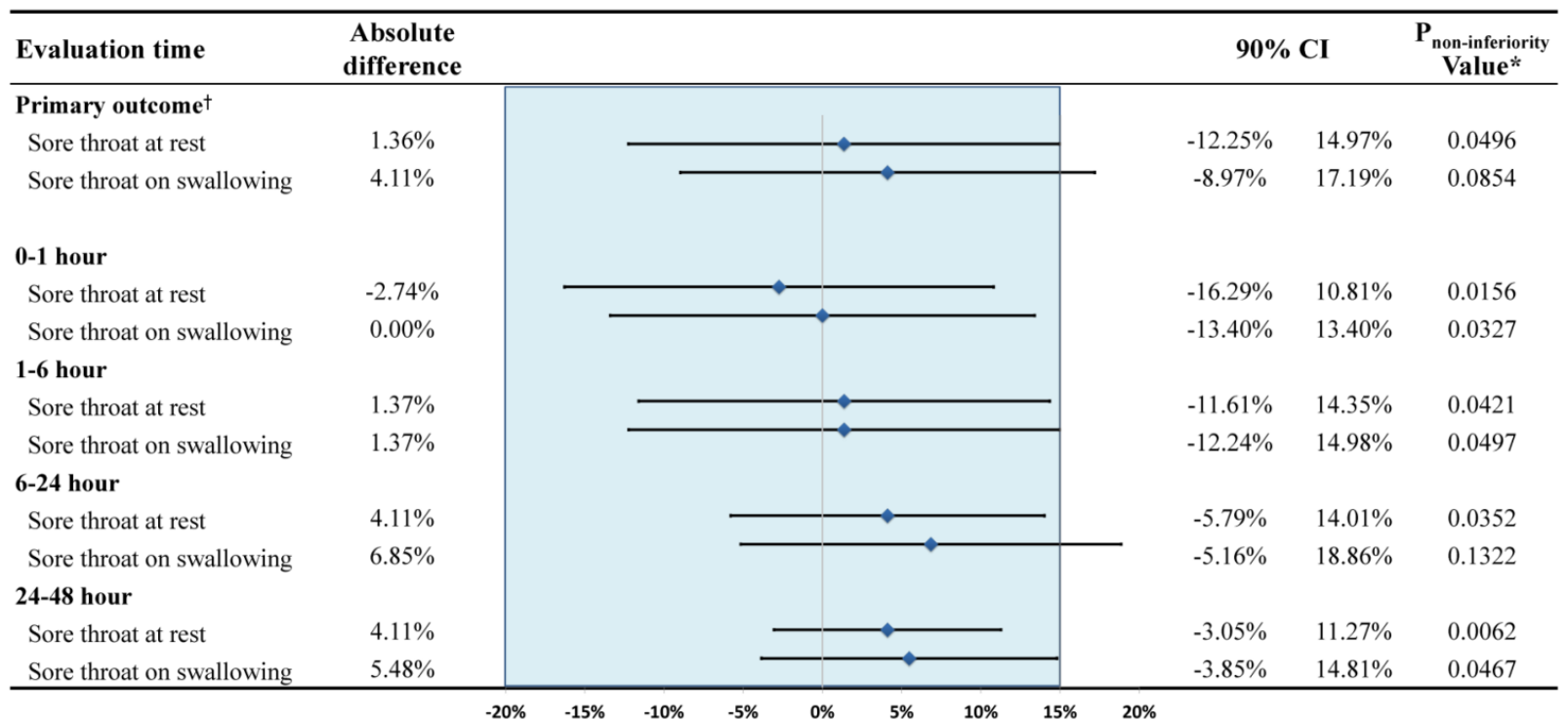

Figure 2. Difference in the incidence of postoperative sore throat. *Against the hypothesis of $15 \%$ difference between the magnesium group and dexamethasone group. Overall incidence of postoperative sore throat. $\mathrm{Cl}$, confidence interval. 


\section{Secondary outcomes}

Postoperative hoarseness occurred in more than half of patient in both group. The incidence and intensity of hoarseness were not statistically significantly different during the study period (Table 3).

The VAS scores for postoperative pain were similar between the groups throughout the study period, whereas more patients in the magnesium group required additional rescue analgesics at time periods of 6 to 24 hours [33 (45.2\%) versus $18(24.7 \%), \mathrm{p}=$ 0.009], and 24 to 48 hours [30 (41.1\%) versus 9 (12.3\%), $\mathrm{p}<0.001)$ ] after operation. Total dose of tramadol for postoperative analgesia was significantly higher in the magnesium group (118 [22-228] $\mathrm{mg}$ ) than in the dexamethasone group (57 [0-95] $\mathrm{mg})(\mathrm{p}=0.001)$. The cumulative volumes of consumed opioid-based PCA were not different between the groups throughout the study period (Table 4).

Table 3. Incidence and severity of hoarseness and the number of patients who required vasoactive drugs

\begin{tabular}{|c|c|c|c|}
\hline & $\begin{array}{l}\text { Magnesium } \\
(\mathrm{n}=73)\end{array}$ & $\begin{array}{l}\text { Dexamethasone } \\
(\mathrm{n}=73)\end{array}$ & $\mathrm{p}$ value \\
\hline \multicolumn{4}{|c|}{ Patients with hoarseness* } \\
\hline Overall incidence & $43(58.9 \%)$ & $42(57.5 \%)$ & 0.867 \\
\hline 0-1 hour & $35(47.9 \%)$ & $36(49.3 \%)$ & 0.868 \\
\hline 1-6 hour & $36(49.3 \%)$ & $30(41.1 \%)$ & 0.318 \\
\hline 6-24 hour & $19(26.0 \%)$ & $15(20.5 \%)$ & 0.433 \\
\hline 24-48 hour & $12(16.4 \%)$ & $6(8.2 \%)$ & 0.131 \\
\hline \multicolumn{4}{|c|}{ Hoarseness severity ${ }^{\dagger}(0 / 1 / 2 / 3)^{*}$} \\
\hline 0-1 hour & $38 / 31 / 4 / 0$ & $37 / 35 / 1 / 0$ & 0.398 \\
\hline 1-6 hour & $37 / 33 / 3 / 0$ & $43 / 26 / 4 / 0$ & 0.484 \\
\hline 6-24 hour & $54 / 18 / 0 / 1$ & $58 / 8 / 5 / 2$ & 0.014 \\
\hline 24-48 hour & $61 / 10 / 0 / 2$ & $67 / 5 / 0 / 1$ & 0.384 \\
\hline \multicolumn{4}{|c|}{ Number of patients who required vasoactive drugs } \\
\hline Ephedrine & $48(65.8 \%)$ & $38(52.1 \%)$ & 0.093 \\
\hline Phenylephrine & $4(5.5 \%)$ & $5(6.8 \%)$ & 0.731 \\
\hline Noradrenaline & $11(15.1 \%)$ & $8(11.0 \%)$ & 0.461 \\
\hline \multicolumn{4}{|c|}{ Values are number of patients (percentage) or median [interquartile range]. } \\
\hline \multicolumn{4}{|c|}{$\begin{array}{l}\text { *The adjusted } p \text { value }<0.0125 \text { was considered significant after Bonferroni correc- } \\
\text { tion. tHoarseness severity, } 0=\text { no hoarseness, } 1=\text { mild hoarseness (noticed by the } \\
\text { patient only), } 2=\text { severe hoarseness (noticed at the time of the interview by the } \\
\text { personnel), } 3=\text { aphonia (inability to speak). }\end{array}$} \\
\hline
\end{tabular}

Blood glucose level after operation was significantly higher in dexamethasone group (136.3 \pm 32.92 $\mathrm{mg} / \mathrm{dL}$ versus $116.1 \pm 21.17 \mathrm{mg} / \mathrm{dL}, \mathrm{p}<0.001)$ while preoperative glucose level was similar between the groups. Level of maximal blood magnesium concentration was 1.85 [1.745-2.015] mg/dL in the magnesium group and $1.33[1.290-1.430] \mathrm{mg} / \mathrm{dL}$ in the dexamethasone group $(\mathrm{p}<0.001)$. The number of $\mathrm{pa}-$ tients who experienced at least one hypotensive event was $53(72.6 \%)$ and $40(54.8 \%)$ in the magnesium group and dexamethasone group, respectively $(\mathrm{p}=$ 0.003 ). In all hypotensive events, blood pressure could be easily restored by predefined measures alone.
Overall incidence of PONV was $35.6 \%$ in the magnesium group and $31.5 \%$ in the dexamethasone group ( $p$ $=0.599$ ). Eleven patients were treated with antibiotics for postoperative wound infection; 5 patients in the magnesium group and 6 patients in the dexamethasone group $(p=0.754)$. Diarrhea was present in one patient in the magnesium group at the second postoperative day, which was spontaneously resolved without any intervention (Table 5).

Table 4. Postoperative analgesic profiles

\begin{tabular}{|c|c|c|c|}
\hline & $\begin{array}{l}\text { Magnesium } \\
(\mathrm{n}=73)\end{array}$ & $\begin{array}{l}\text { Dexame- } \\
\text { thasone } \\
(\mathrm{n}=73)\end{array}$ & $\mathrm{p}$ value \\
\hline \multicolumn{4}{|l|}{$\begin{array}{l}\text { VAS scores of pain (at rest/ at mov- } \\
\text { ing)* }\end{array}$} \\
\hline 0-1 hour & $\begin{array}{l}4[2-6] / 5 \\
{[3-7]}\end{array}$ & $\begin{array}{l}4[3-6] / 5 \\
{[3-7]}\end{array}$ & $\begin{array}{l}0.731 / \\
0.791\end{array}$ \\
\hline 1-6 hour & $\begin{array}{l}3[2-5] / 5 \\
{[3-7]}\end{array}$ & $\begin{array}{l}3[3-5] / 5 \\
{[4-7]}\end{array}$ & $\begin{array}{l}0.534 / \\
0.530\end{array}$ \\
\hline 6-24 hour & $\begin{array}{l}3[2-4] / 4 \\
{[3-6]}\end{array}$ & $\begin{array}{l}3[2-3] / 4 \\
{[3-5]}\end{array}$ & $\begin{array}{l}0.056 / \\
0.335\end{array}$ \\
\hline 24-48 hour & $\begin{array}{l}2[2-3] / 3 \\
{[3-5]}\end{array}$ & $\begin{array}{l}2[1-3] / 3 \\
{[2-4]}\end{array}$ & $\begin{array}{l}0.398 / \\
0.134\end{array}$ \\
\hline \multicolumn{4}{|c|}{ Number of patients who required analgesics* } \\
\hline Overall & $55(75.3 \%)$ & $47(64.4 \%)$ & 0.149 \\
\hline 0-1 hour & $26(35.6 \%)$ & $20(27.4 \%)$ & 0.285 \\
\hline 1-6 hour & $30(41.1 \%)$ & $27(37.0 \%)$ & 0.611 \\
\hline 6-24 hour & $33(45.2 \%)$ & $18(24.7 \%)$ & 0.009 \\
\hline 24-48 hour & $30(41.1 \%)$ & $9(12.3 \%)$ & $<0.001$ \\
\hline $\begin{array}{l}\text { Total tramadol dose for pain rescue } \\
(\mathrm{mg})\end{array}$ & $118[22-228]$ & $57[0-95]$ & 0.001 \\
\hline \multicolumn{4}{|l|}{$\begin{array}{l}\text { Cumulative volume of PCA con- } \\
\text { sumed }(\mathrm{mL})^{*}\end{array}$} \\
\hline 0-1 hour & $1[0-2]$ & $1[0-2]$ & 0.752 \\
\hline 1-6 hour & $15[13.5-20]$ & $15[14-20]$ & 0.383 \\
\hline 6-24 hour & $60[50-62.5]$ & $58[50-60]$ & 0.652 \\
\hline 24-48 hour & 100 [95-100] & 100 [100-100] & 0.216 \\
\hline
\end{tabular}

Table 5. Complications associated with the studied drugs

\begin{tabular}{llll}
\hline & $\begin{array}{l}\text { Magnesium } \\
(\mathrm{n}=73)\end{array}$ & $\begin{array}{l}\text { Dexamethasone } \\
(\mathrm{n}=73)\end{array}$ & $\begin{array}{l}\mathrm{p} \\
\text { value }\end{array}$ \\
\hline Preoperative glucose $(\mathrm{mg} / \mathrm{dL})$ & $98.3 \pm 13.89$ & $102.0 \pm 14.91$ & 0.122 \\
Postoperative glucose $(\mathrm{mg} / \mathrm{dL})$ & $116.1 \pm 21.17$ & $136.3 \pm 32.92$ & $<0.001$ \\
Maximal magnesium $(\mathrm{mg} / \mathrm{dL})$ & 1.85 & 1.33 & $<0.001$ \\
& {$[1.745-2.015]$} & {$[1.290-1.430]$} & \\
Perioperative hypotension & $53(72.6 \%)$ & $40(54.8 \%)$ & 0.003 \\
Vasopressor use & $49(67.1 \%)$ & $38(52.1 \%)$ & 0.064 \\
Postoperative nausea and vomit- & $26(35.6 \%)$ & $23(31.5 \%)$ & 0.599 \\
ing & & & \\
Postoperative wound infection & $5(6.8 \%)$ & $6(8.2 \%)$ & 0.754 \\
Diarrhea & $1(1.4 \%)$ & $0(0.0 \%)$ & $>0.999$ \\
\hline
\end{tabular}

Values are number of patients (percentage), mean \pm standard deviation or median [interquartile range]. 


\section{Discussion}

In this prospective, double-blind, randomized, and non-inferiority trial, we could not observe any statistically significant differences in the incidence and severity of POST between the magnesium and dexamethasone group in patients undergoing lumbar spinal surgery in the prone position. The majority of patients in both groups presented POST VAS scores of less than 3. In addition, the incidence and severity of hoarseness were also not different between the groups. Non-inferiority analysis using the upper limit of the $90 \%$ confidence interval revealed that magnesium sulphate appears to be non-inferior to dexamethasone for the prevention of POST at rest in this subset of patients.

Albeit the clinicians have perceived POST as a natural consequence of tracheal intubation rather than complication [20], it may significantly affect the quality of life and satisfaction of patients during the recovery period [21]. Consequently, increasing efforts for preventing or minimizing the occurrence of POST during the postoperative recovery period have been attempted [1], while no conclusive measures were elucidated yet, especially in patients undergoing lumbar spinal surgery.

Since POST is mainly mediated by an inflammatory response causing airway mucosal trauma or tissue damage [1], and is a sort of postoperative pain frequently aggravated with PONV [6], pharmacologic agents possessing anti-inflammatory, anti-nociceptive, and anti-emetic effects would be ideal for the prevention and treatment of POST. Various agents have been examined for POST such as dexamethasone [2], inhaled beclomethasone [11], benzydamine hydrochloride spray [22], or transdermal ketoprofen with controversial results [23]. Among them, dexamethasone showed promising results [24], which might be attributable to its multidisciplinary mechanisms. Magnesium also has a theoretical potential to reduce POST in terms of anti-inflammatory [25] and anti-nociceptive effect [16], though the effect on PONV was controversial. Recently, magnesium showed a beneficial effect on POST at a clinically relevant dose without complications [16]. Therefore, we compared the effects of magnesium and dexamethasone on POST in patients undergoing lumbar spinal surgery in the prone position, who are at increased risk of developing POST, which has not been addressed heretofore. Since the studied patients were at increased risk of developing POST, we designed a non-inferiority trial to avoid establishment of placebo-control group.

As our results indicate, the incidence and severity of POST were all similar between the groups at all time points of assessment. Non-inferiority analysis revealed that magnesium sulphate was non-inferior to dexamethasone for the prevention of POST in terms of the overall incidence at rest, whereas it only showed a trend towards being non-inferior in terms of the overall incidence on swallowing $(\mathrm{p}=0.0854)$. However, detailed analysis revealed that magnesium sulphate was non-inferior to dexamethasone at all serially assessed time points of measurement except at 6-24 $\mathrm{h}$ on swallowing, which implicates the non-inferiority of magnesium sulphate to dexamethasone regarding the prevention of POST.

Of note, the overall incidence of POST during study period was more than $60 \%$ in both groups despite the use of potentially preventive medications, whereas the majority of patients in this study presented very low VAS scores for POST in comparison with previous studies $[2,6,12]$. The median VAS score of 1 for POST implies that the patient did not perceive POST until they were interviewed. Nonetheless, patients were considered as having POST as long as the VAS score was $\geq 1$ in the current study. Therefore, the high incidence of POST in this study should not discourage the use of both studied drugs as most of the patients had a VAS score of less than 3. Indeed, the overall incidence of patients with POST VAS score of higher than 4 was only $15.1 \%$ and $16.4 \%$ in the magnesium group and dexamethasone group, respectively $(p=0.820)$. Thus, these results implicate that both magnesium sulphate and dexamethasone could effectively mitigate the development of clinically significant POST in this high-risk group of patients.

Notably, patients treated with dexamethasone required less rescue analgesics during 6 to 24 hours, and 24 to 48 hours after operation with comparable cumulative infused volume of PCA and VAS scores for pain compared with the patients in the magnesium group. Beneficial effect of dexamethasone to reduce postoperative pain and analgesic requirement in various surgical patients [26] including lumbar spinal surgical patients [27] have been well documented. On the contrary, the effect of magnesium sulphate on postoperative pain is still controversial $[28,29]$, while some studies reported better pain relief with intraoperative magnesium sulphate compared to placebo $[15,30]$. Direct comparison between the magnesium sulphate and dexamethasone against postoperative pain has not been addressed yet, and the result of this study demonstrated superior efficacy of dexamethasone over magnesium sulphate in reducing postoperative pain.

The PONV is known to increase the susceptibility of pain [31,32], and is frequently accompanied with POST [6]. Among the available anti-emetics, dexamethasone has been extensively studied and widely used for the reduction of PONV [33]. The ef- 
ficacy of magnesium on antiemetic prophylaxis for PONV is not quite satisfactory heretofore [30]. In this study, however, both drugs exerted comparable efficacy on the severity as well as the incidence of PONV throughout the study period.

One of the concerns of using dexamethasone is the potential for poor glycemic control. In this study, postoperative glucose level measured at immediate postoperative period was higher in the dexamethasone group. The clinical significance of this minor increase in blood glucose level in the dexamethasone group is beyond the scope of this study to discuss and remains to be proven. Considering the results of the current trial, magnesium sulphate could be a valuable option for the prevention of POST when the use of dexamethasone may not be appropriate for its potential side-effects.

This study is subject to following limitations. Since we excluded patients with expected difficult intubation to control confounding variables, generalization of this result should be exercised with caution. While the dose of magnesium sulphate was determined based on the estimated safe dose without hemodynamic consequences, the dose of magnesium used in this study might not be an optimal dose for POST, which merits further studies in that regard. Likewise, same limitation applies to the chosen dose of dexamethasone in this study.

In conclusion, prophylactic magnesium sulphate appears to be non-inferior to dexamethasone for prevention of POST at rest in patients undergoing lumbar spinal surgery in the prone position.

\section{Acknowledgements}

We would like to thank our statistical assistant Jinae Lee, Instructor (Senior Biostatistician) of Biostatistics Collaboration Unit in Yonsei University College of Medicine, for her help with data analysis.

\section{Competing Interests}

The authors have declared that no competing interest exists.

\section{References}

1. McHardy FE, Chung F. Postoperative sore throat: cause, prevention and treatment. Anaesthesia 1999; 54(5):444-53.

2. Park SH, Han SH, Do SH, Kim JW, Rhee KY, Kim JH. Prophylactic dexamethasone decreases the incidence of sore throat and hoarseness after tracheal extubation with a double-lumen endobronchial tube. Anesth Analg 2008; 107(6):1814-8

3. Mokhtar AM, Choy CY. Postoperative sore throat in children: comparison between proseal LMA and classic LMA. Middle East J Anaesthesiol 2013; 22(1):65-70.

4. Ayoub CM, Ghobashy A, Koch ME, McGrimley L, Pascale V, Qadir S, et al. Widespread application of topical steroids to decrease sore throat, hoarseness, and cough after tracheal intubation. Anesth Analg 1998; 87(3):714-6.

5. Stout DM, Bishop MJ, Dwersteg JF, Cullen BF. Correlation of endotracheal tube size with sore throat and hoarseness following general anesthesia. Anesthesiology 1987; 67(3):419-21.

6. Biro P, Seifert B, Pasch T. Complaints of sore throat after tracheal intubation: a prospective evaluation. Eur J Anaesthesiol 2005; 22(4):307-11.
7. Hari Kumar S, Saravanan D, Ranganathan S, Sumathi K. Post-operative sore throat-Incidence and contributory factors. Journal of pharmaceutical and biomedical sciences 2013; 26(26):286-92.

8. Koshy E, Curcin V, Bottle A, Sharland M, Saxena S. Sore throat consultations in general practice prior to tonsillectomy among eight hundred and sixty-three children in England: is this in accordance with the SIGN guidelines? Clin Otolaryngol 2013; 38(3):266-70.

9. Dimitriou VK, Zogogiannis ID, Douma AK, Pentilas ND, Liotiri DG, Wachtel MS, et al. Comparison of standard polyvinyl chloride tracheal tubes and straight reinforced tracheal tubes for tracheal intubation through different sizes of the Airtraq laryngoscope in anesthetized and paralyzed patients: a randomized prospective study. Anesthesiology 2009; 111(6):1265-70.

10. Loeser EA, Bennett GM, Orr DL, Stanley TH. Reduction of postoperative sore throat with new endotracheal tube cuffs. Anesthesiology 1980; 52(3):257-9.

11. el Hakim M. Beclomethasone prevents postoperative sore throat. Acta Anaesthesiol Scand 1993; 37(3):250-2.

12. Thomas S, Beevi S. Dexamethasone reduces the severity of postoperative sore throat. Can J Anaesth 2007; 54(11):897-901.

13. Nicholson G, Burrin JM, Hall GM. Peri-operative steroid supplementation. Anaesthesia 1998; 53(11):1091-104

14. Koinig H, Wallner T, Marhofer P, Andel H, Horauf K, Mayer N. Magnesium sulfate reduces intra- and postoperative analgesic requirements. Anesth Analg 1998; 87(1):206-10.

15. Tramer MR, Schneider J, Marti RA, Rifat K. Role of magnesium sulfate in postoperative analgesia. Anesthesiology 1996; 84(2):340-7.

16. Borazan H, Kececioglu A, Okesli S, Otelcioglu S. Oral magnesium lozenge reduces postoperative sore throat: a randomized, prospective, placebo-controlled study. Anesthesiology 2012; 117(3):512-8.

17. Gupta SK, Tharwani S, Singh DK, Yadav G. Nebulized magnesium for prevention of postoperative sore throat. Br J Anaesth 2012; 108(1):168-9.

18. Oguzhan N, Gunday I, Turan A. Effect of magnesium sulfate infusion on sevoflurane consumption, hemodynamics, and perioperative opioid consumption in lumbar disc surgery. J Opioid Manag 2008; 4(2):105-10.

19. Harding CJ, McVey FK. Interview method affects incidence of postoperative sore throat. Anaesthesia 1987; 42(10):1104-7.

20. Beebe DS. Complications of Tracheal Intubation. Seminars in Anesthesia, Periaperative Medicine and Pain 2001; 20(3):166-72.

21. Macario A, Weinger M, Carney S, Kim A. Which clinical anesthesia outcomes are important to avoid? The perspective of patients. Anesth Analg 1999; 89(3):652-8.

22. Huang YS, Hung NK, Lee MS, Kuo CP, Yu JC, Huang GS, et al. The effectiveness of benzydamine hydrochloride spraying on the endotracheal tube cuff or oral mucosa for postoperative sore throat. Anesth Analg 2010; 111(4):887-91.

23. Ozaki M, Minami K, Sata T, Shigematsu A. Transdermal ketoprofen mitigates the severity of postoperative sore throat : [Le ketoprofene transdermique reduit le mal de gorge postoperatoire]. Can J Anaesth 2001; 48(11):1080-3.

24. Wei JL, Kasperbauer JL, Weaver AL, Boggust AJ. Efficacy of single-dose dexamethasone as adjuvant therapy for acute pharyngitis. Laryngoscope 2002; 112(1):87-93

25. Mazur A, Maier JA, Rock E, Gueux E, Nowacki W, Rayssiguier Y. Magnesium and the inflammatory response: potential physiopathological implications. Arch Biochem Biophys 2007; 458(1):48-56.

26. De Oliveira GS, Jr., Almeida MD, Benzon HT, McCarthy RJ. Perioperative single dose systemic dexamethasone for postoperative pain: a meta-analysis of randomized controlled trials. Anesthesiology 2011; 115(3):575-88.

27. Watters WC, 3rd, Temple AP, Granberry M. The use of dexamethasone in primary lumbar disc surgery. A prospective, randomized, double-blind study. Spine (Phila Pa 1976) 1989; 14(4):440-2.

28. Bhatia A, Kashyap L, Pawar DK, Trikha A. Effect of intraoperative magnesium infusion on perioperative analgesia in open cholecystectomy. J Clin Anesth 2004; 16(4):262-5.

29. Ko SH, Lim HR, Kim DC, Han YJ, Choe H, Song HS. Magnesium sulfate does not reduce postoperative analgesic requirements. Anesthesiology 2001; 95(3):640-6.

30. Albrecht E, Kirkham KR, Liu SS, Brull R. Peri-operative intravenous administration of magnesium sulphate and postoperative pain: a meta-analysis. Anaesthesia 2013; 68(1):79-90.

31. Rabasseda X. Ramosetron, a 5-HT3 receptor antagonist for the control of nausea and vomiting. Drugs Today (Barc) 2002; 38(2):75-89.

32. Lu K-z, Shen H, Chen Y, Li M-g, Tian G-p, Chen J. Ondansetron does not attenuate the analgesic efficacy of nefopam. International journal of medical sciences 2013; 10(12):1790.

33. Henzi I, Walder B, Tramer MR. Dexamethasone for the prevention of postoperative nausea and vomiting: a quantitative systematic review. Anesth Analg 2000; 90(1):186-94. 